\title{
The Content Management Handbook
}

\author{
Martin White, Facet Publishing, London, 2005, 149 pages, £39.95 (Hardback)
}

\author{
George Macgregor \\ Centre for Digital Library Research \\ University of Strathclyde
}

It goes without saying that some comprehensive books already exist in the area of content management, most notably the Content Management Bible (Boiko, 2004). Yet, for many, the idea of 'content management' remains a relatively new concept and there is consequently much advice to share when it comes to how best to develop a content strategy or implement a content management system. When compared to the likes of Boiko's 1170 page Bible, the Content Management Handbook is a relatively slim volume at 139 pages (not including references), and rather than competing with Boiko et al, author Martin White purports to complement such books. .

To this end White assumes a 'project management' view of what is involved in bringing a content management strategy to fruition. As White states: "Without a content management strategy (CMS) there cannot be a content management system (CMS) and without a content management system (CMS) there is no point in implementing content management software" (p.xi). The Content Management Handbook therefore explores the development of a content management strategy; the various technical approaches to content management; specifying system requirements and selecting appropriate vendors, and; procurement and implementation of the system proper. Chapters on making the business case for a content management system and on system migration are also provided, as are useful end-of-chapter summaries.

The intention of any handbook is to keep the practitioner on the straight and narrow, and occasionally this requires a statement of the obvious. Indeed, some of the advice errs on the side of common sense (e.g. "The development of a content management strategy requires careful preparation and should be carried out on a collaborative basis"). But such summary statements are welcome and should not be construed as patronising; even the most information savvy CMS manager can lose his/her ability for rational thought during a tumultuous system implementation process.

That White has the credentials is indisputable. He is, after all, Managing Director of Intranet Focus Ltd, a company he founded in 1999, and he has presided over many large scale content management projects. The Department of Information Studies at the University of Sheffield also have White as a Visiting Professor and the CMS Evaluation Laboratory at the iSchool have him sitting on their Advisory Board. This wealth of experience is reflected in the inclusion of numerous case studies, useful checklists and guidance on conducting information audits, planning for vendor presentations, drafting system specifications, and so forth.

Be that as it may, some crucial areas of content management appear to evade adequate exposition. For example, metadata, we are told, "is at the heart of a content management system"; yet it only receives three and a half pages (including a table of the Dublin Core Metadata Element set) and little more than a rudimentary definition is provided. Even more regrettably, there is a dearth of appropriate metadata references. This is symptomatic of the referencing generally, which is inadequate in breadth or scope and continually refers the reader to the same few resources. Even the final chapter - which is dedicated to providing the reader with a list of further resources - is quite limited. Such instances tend to make the Content Management Handbook less of a handbook and more of an introduction.

It is also worth stating what this book is not. It is not concerned with the management of learning objects, or the use of content management systems to support the management and delivery of simple or complex digital objects, as characterised by Yan (2004). The Content Management Handbook concentrates squarely on the conventional virtues of content management within large websites or intranets (i.e. the automation or facilitation of web publishing and the general life-cycle management of such information) and the specification and procurement procedures therein. And there is a sense in which Facet have missed a golden opportunity to provide the library and information profession with 
an altogether more wide-ranging - and perhaps seminal - handbook; one that encompasses content management in its various permutations. The slim monograph would obviously grow to obese Boikoesque proportions but, as we have learned from the high premium Western society places on notions of attractiveness, being thin - although occasionally desirable - is not the be all and end all. Still, being thin and concentrating on one type of content management was clearly the brief for White and, providing some of the above caveats are noted, the Content Management Handbook remains a useful text for those requiring a whirlwind content management introduction and advice on avoiding the hazards that so commonly befall other less informed practitioners.

\section{References}

Boiko, B. (2004), Content Management Bible, Hungry Minds Inc., New York.

Han, Y. (2004), "Digital content management: the search for a content management system", Library Hi-Tech, Vol. 22 No. 4, pp.355-365. 